Additionally, the book provides useful pictures and diagrams. Some diagrams are very detailed and do provide a useful adjunct to the text. They also help to split up the written prose making reading easier and the use of colour helps draw attention to relevant points. The book uses coloured text boxes to highlight important subject matter. The box at the start of each chapter providing an overview of its structure, aims and objectives is particularly useful. The book has a definite dental 'feel' to it as the author continually revisits the dental relevance of topics discussed within each chapter. This is achieved in a very fluent way. The dental relevance is not simply added in at the end of each chapter, but is provided as a recurring theme throughout.

This book would primarily benefit undergraduate dental students. As mentioned in the preface, many students will undergo a course in general biochemistry, but the dental relevance of some topics covered may be difficult to comprehend - something that this book manages to overcome. This is reinforced particularly in the later chapters which focus on saliva, periodontitis, caries and fluoride. These not only expand on areas covered in earlier chapters, but they are also extremely useful in understanding principles of biochemistry applied to key dental topics.

In summary, this book is an extremely useful resource. It provides a wealth of information useful to both undergraduates and those wishing to refresh their knowledge of topics in dental biochemistry.

\title{
Mouth Cancer Action takes fight to Westminster
}

On 15 November a special event was held at the House of Commons in support of Mouth Cancer Action Month. It was attended by those personally affected by mouth cancer, Members of Parliament, the dental and wider health profession and supporters and campaigners of mouth cancer action.

Dr Nigel Carter OBE, CEO of the Oral Health Foundation, spoke at the event about the increase in mouth cancer cases in recent years and how important Mouth Cancer Action Month is in bringing the issue to a wide audience: 'Mouth Cancer Action Month is an important opportunity to raise vital public awareness of the disease and potentially catch many hundreds of cases in the future before it is too late.

Keynote speaker Professor Michael Lewis drew attention to the emerging trends in mouth cancer, including the growing evidence that more women and younger people are being diagnosed with the disease. He also highlighted that size does indeed matter when it comes to mouth cancer, as a patient's survival chance is often based upon when their case is diagnosed, showing that early diagnosis significantly improves a patient's prognosis.

Professor Lewis also called upon everybody to add their support to the important campaign for a gender-neutral HPV vaccination which has the potential to save thousands of lives lost to mouth cancer in the future.

If you have not done so yet there is still time to pledge your support to the campaign and take part in Mouth Cancer Action Month, visit

www.mouthcancer.org/support to sign up now. 